\title{
Reduced Audit Quality Behavior Scale: Exploratory and Confirmatory Analysis Based on a Sample of External Auditors in Uganda
}

\author{
Gerald Kasigwa \\ Makerere University Business School, Uganda \\ gbkasigwa@gmail.com
}

\begin{abstract}
Reduced Audit quality Behavior (RAQB) has been linked to poor quality audits. Whereas reduce audit quality behavior has been studied for some time in developed countries, there has been little empirical research effort in least developed countries like Uganda geared towards understanding and operationalizing the factor structure of reduced audit quality acts. This research set out to establish and confirm a reliable and valid factor structure of reduced audit quality behavior. Data were collected from 351 certified public accountants (CPA's) practicing as external auditors in Uganda. Exploratory factor Analysis produced a five factor model; with confirmatory factor analysis demonstrating good fit statistics. The reliability of the scales as measured by Cronbach's alpha, construct reliability and average variance extracted was higher than the recommended minimum values confirming that reduced audit quality acts can be proxied by two dimensions namely; quick review and examination. Researchers in Uganda are advised to use these proxies while studying reduced audit quality behavior.
\end{abstract}

Keywords: Reduced Audit Quality Behavior, Exploratory Factor Analysis, Confirmatory Factor Analysis, Reliability, Validity, Dimension, Certified Public Accountants

\section{Introduction}

Uganda has one of highest perceived levels of corruption after scoring 26 on the 2013 Transparency International corruption scale. The index scores 177 countries on a scale from 0 (highly corrupt) to 100 (very clean). This placed Uganda in position number 140 out of 177 countries, making it one of the worst performing countries. Although, there has been a lot of effort by the Government of Uganda to put a stop to this vice, it is still continues resulting in loss of vast resources. The auditing profession in Uganda is one of those that have faced a lot of criticism because of their failure to detect cases of fraud both in Government and private institutions. Mwenda (2013) reported that between 2009 and 2012, a total of shs. 340 billion meant to be paid to former retired Government of Uganda workers as pension had been paid to 3000 non existing workers, and shs. 60 billion had been misappropriated in the Office of the Prime Minister during the financial years 2010/11 and 2011/12. He wondered how possible it was for officials from the office of the Prime Minister, Accountant General's office, central Bank, internal and external auditors to collude to have this money siphoned without any detection. Auditors' failures to report frauds have been linked to reduced audit quality behavior. Kasigwa, Munene Ntayi \& Nkote (2013) found that reduced audit quality behavior was a widespread problem among external auditors in Uganda. Malone \& Roberts (1996) defined Reduced Audit Quality acts as intentional acts by the auditor that reduces evidence gathering inappropriately, and they have been found to have negative consequences on the audit quality (Public Oversights Board, 2000). In the examination of reduced audit quality behavior, most studies have been carried out in the developed countries, and least developed countries like Uganda have been greatly under researched, despite the fact that they are affected by auditors' reduced audit quality behavior.

Prior research, mainly carried out in the developed countries, has shown that reduced audit quality behavior has been operationalised as a uni-dimensional construct. However, some scholars have argued that specific acts differ in their level of occurrence and acceptance (see Malone \& Roberts, 1996; Willet \& Page, 1996; Otley \& Pierce, 1996; Herrbach, 2001). Coram et al. (2008) found that reduced audit quality acts do differ in terms of their "moral intensity" and this could explain why some acts are more prevalent than others. If reduced audit quality acts differ in their underlying attributes, then aggregating data from different acts may cofound results and conclusions may also differ depending on the reduced audit quality act chosen. Distinguishing the 
various dimensions of reduced audit quality acts both conceptually and empirically should be beneficial to the profession and Government of Uganda, as it will provide insights into acts that auditors regularly engage in, which will assist in identifying ways to minimize this behavior. The purpose of this study was to investigate the dimensions that constitute reduced audit quality behavior which can be used as proxies in the study of reduced audit quality behavior in Uganda.

\section{Literature Review}

According to Malone \& Roberts (1996), reduced audit quality behaviors are "actions taken by an auditor during an engagement which reduce evidence gathering effectiveness inappropriately". This behavior is referred to as dysfunctional audit behavior by Donnelly, O'Bryan \& Quirin, (2003), and they refer to it as certain actions of auditor that encourage sub-standard audit. Otley \& Pierce (1996a) refer to these behaviors as audit quality reduction behavior, while Pierce \& Sweeney (2004) refer to them as "Quality threatening behavior". Reduced audit quality behaviors that occur in audit practice include: pre-mature sign off or falsely signing off a required step, which is not covered by other audit steps, without completing the work or noting the omission of procedures (Paino et al., 2010, 2011; Coram et al., 2008; Margheim et al., 2005; McNamara \& Liyanarachchi, 2005; Otley \& Pierce, 1996a; Kelly \& Margheim, 1990; Raghunathan, 1991); accepting weak client explanations as a substitute for evidence that would be available (Paino et al., 2010, 2011 \& 2012; Coram et al., 2008; Margheim et al., 2005; McNamara \& Liyanarachchi, 2005; Coram et al., 2003; Otley \& Pierce, 1996a; Kelly \& Margheim, 1990), making superficial reviews of client documents (Paino, et al., 2010, 2011 \& 2012; Coram et al., 2008; Margheim et al., 2005; McNamara \& Liyanarachchi, 2005; Coram et al., 2003; otley \& Pierce, 1996a; Kelly \& Margheim, 1990; Pierce \& Sweeney, 2004); and failing to adequately research accounting principles (Paino et al., 2010, 2011; Coram et al., 2008; Margheim et al., 2005; McNamara \& Liyanarachchi, 2005; otley \& Pierce, 1996a; Kelly \& Margheim, 1990; Pierce \& Sweeney); rejecting awkward-looking items from a sample (Coram et al., 2008; Coram et al., 2003; Willet \& page, 1996), greater than appropriate reliance on clients' work (Pierce \& Sweeny, 2004), and not pursuing questionable items (McNair, 1991); under-reporting actual time spent on the audit (Otley \& Pierce, 1996a; Lightner et al., 1982; Rhode, 1978)

According to Herrbach (2001), specific acts that constitute reduced audit quality behavior differ in their levels of occurrence. Coram et al. (2008) found that reduced audit acts differ in terms of their moral intensity. They found that there were differences in perception about reduced audit quality acts in terms of probability of effect to auditors and the magnitude of consequences to auditors. These results suggest that reduced audit quality acts differ in terms of their "moral intensity" and this could explain why some acts are more prevalent than others. Malone \& Roberts (1996) reported that 25 percent of the auditors surveyed admitted to falsely signing off, 42 percent admitted to not researching a technical issue, while 48 percent admitted to superficially reviewing supporting documents. Fifty percent had failed to pursue questionable items, while 58 percent had accepted weak client explanation from their clients. Only 26 percent of auditors had never done less work than normal. Paino et al. (2010), found that 57 per-cent of 244 auditors surveyed in Malaysia admitted to signing off pre-maturely. Kasigwa et al. (2013) found that 94 percent of 313 external auditors in Uganda admitted to engaging in reduced audit quality behavior. Although, Coram et al. (2008) argued that reduced audit quality acts differ in their moral intensities, and other scholars have shown that different reduced audit quality acts have different levels of occurrence (Herrbach, 2001). Previous studies have treated reduced audit quality behavior as a uni-dimensional construct with a number of acts (e.g. Paino et al., 2011; Paino et al., 2010; Paino et al., 2010; Margheim et al., 2005; Otley \& Perce, 1996; McNamara \& Liyanarachchi, 2005; Kelly \& Margheim, 1990), while others have treated it as a one item construct (e.g. Lightner et al., 1982; Rhode, 1978). This study agrees with Coram et al. (2008) and Herrbach (2001) and hypothesized that:

H1: Reduced audit quality behavior is a multi-dimension construct.

\section{Methodology}

This section discusses the research methods and design used in this study. 
Research Design: The quantitative research was the preferred approach for this research based on nature of the research. Drawing on the existing literature on reduced audit quality behavior, this study sought to establish the factor structure of reduced audit quality acts based on the seven acts frequently cited in the literature and used by Coram et al. (2003). Punch (1998) maintains that the methods used to conduct the research should be in line with the research questions. Therefore, a quantitative approach was carried out in this study to test the hypotheses and then to answer the research questions. While quantitative methodology is unable to generate theory or provide the in-depth explanations of qualitative enquiry, Cavana, Delahaye and Sekaran (2001) and Amaratunga Bary, Sashar \& Newton (2002) point out that it can verify the hypotheses and provide strong reliability and validity. Added to this, quantitative methodology has been successfully used in studies on reduced audit quality behavior. The study also employed a cross sectional survey design. In a cross-sectional study, a particular phenomenon is studied at a particular period of time. Cross sectional designs are suited for studies aimed at finding out the prevalence of a phenomenon, situation, problem, or attitude, by taking a cross-section of the population at a given time. This being a behavioral study, a cross sectional design was ideal.

Scale development: Reduced audit quality behavior was measured using Coram et al. (2008) questionnaire. The questionnaire identified the seven reduced audit quality acts most commonly cited in prior reduced audit quality behavior literature (Malone \& Roberts, 1996; Otley \& Pierce, 1996; Herrbach, 2001). However, Coram et al. (2008) questionnaire used one item to measure each reduce audit quality act, and single items have been criticized by Churchill (1979) as: 1) lacking sufficient correlation with the attribute being measured, 2) closely related to other attributes, 3) restricted variance of scale, and unreliable responses. In accordance with Churchill (1979) and Peter (1979), an item asking auditors to state the extent they thought other auditors engaged in a particular reduced audit quality act was added to each item making a two-item questionnaire for each act in order to provide a comprehensive evaluation and help the researcher to overcome the shortcoming of a single item measure. Multi-item scales are considered necessary to achieve valid measurement of factorially complex constructs (Peter, 1979). Single-item scales were modified for this study to better reflect auditors' perspectives in an audit context. These modified items were validated by conducting pre-test procedures. In this section, all the underlying constructs in the proposed theoretical model are presented, and items used to measure them are discussed. The fourteen items using a five point scale, anchored by "Always $=1$, Often $=2$, Sometimes $=3$, Rarely $=4$ and Never $=5$ ".

Pre-Test: A pilot study was conducted to assess the reliability and validity of the proposed instrument. The instrument was distributed to 65 internal auditors both in the public and private sectors. Of the 65 questionnaires 59 were returned representing $97 \%$ response rate. Out of the 59 returned, 7 were found to be incomplete. Hunt, Sparkman and Wilcox (1982, p.270) suggests that a researcher should always find out if the research instrument can generate quality data to address the research objectives. The benefits of a pretest prior to conducting the main survey have been supported by numerous researchers (see Hunt et al., 1982; Saunders, Lewis \& Thornhill, 2009). Zikmund, Babin \& Griffin (2010, p.233) defines a pre-test as "a trial run with a group of respondents used to screen out problems in the instructions or design of a questionnaire" p.233). He proposes three ways to pre-test an instrument. The first two involve the use of research professionals to screen the questionnaire, and the third one, a trial run with a group of respondents. In the first two the researcher requests research professionals to look at difficulties in wording, leading questions and bias due to question order. This study used expert panel, interviews and planned field survey methods to pre-test the questionnaire. Multiple methods were used because of the limitations associated with each of the pre-test methods. The draft instrument was first distributed to a panel of four experts, who included two auditing lecturers and two experienced external auditors. They were requested to assess the questionnaire in terms of conceptualization of the constructs and wording, since there were no serious changes recommended, the instrument was not altered. The second procedure involved interviewing five experienced auditors. The auditors were expected to identify any problems in the questionnaire format, wording or design. In the fourth and final procedure, questionnaires were distributed to internal auditors. In total, 65 questionnaires were distributed. To assess the reliability of the measures, Cronbach's coefficient alpha was examined, showing that all scale items had high alpha scores exceeding 0.6. As no major modifications were made to the instrument, a further pre-test was considered unnecessary. 
Population and sample: A total of 400 questionnaires were distributed to Certified Public Accountants (CPA's) involved in external auditing of private and public entities in Uganda. A total of 352 questionnaires were returned representing a response rate of 89.2 percent

\section{Results}

This section sets out the results from data analysis

Sample characteristics: The results shown in Table 2 indicate differences in the demographics of the respondents including gender, age, educational qualification, audit working experience and position in the firm nights. As can be seen, the analysis of the final sample profile showed a higher number of male respondents than female, representing a ratio of $69.7 \%$ and $30.3 \%$, respectively. The mean age of respondents in this thesis was 44.7 years, while 62.4 percent of the respondents had bachelor's degrees. The majority of respondents were auditors (49.5\%), senior auditors were (25.6\%). Most respondents had auditing experience of 4-6 years (31.9\%), while those of 0-3 years were (24.9\%)

\section{Table 2: Profile of Respondents: Number of Respondents ( $N=313$ )}

\begin{tabular}{lll}
\hline Item & Frequency & Percentage \\
\hline Gender & 217 & 69.3 \\
Male & 96 & 30.7 \\
Female & & \\
Age & 55 & 17.6 \\
18-28 & 132 & 42.2 \\
$29-39$ & 98 & 31.3 \\
40-50 & 28 & 8.9 \\
Over 50 & & \\
Marital status & 69 & 22 \\
Single & 187 & 59.7 \\
Married & 43 & 13.7 \\
Living together & 7 & 2.2 \\
Divorced & 6 & 1.9 \\
Widow/Widower & & \\
& & \\
Level of education & 23 & 7.4 \\
Diploma & 194 & 62.4 \\
Bachelor's & 77 & 24.8 \\
Master's & 17 & 5.5 \\
Other & & \\
Auditing Experience & 78 & 24.9 \\
0-3 years & 100 & 31.9 \\
4-6 & 51 & 16.3 \\
7-10 & 84 & 26.8 \\
Over 10 & & \\
Position & 155 & 49.5 \\
Auditor & 80 & 25.6 \\
Senior Auditor & 45 & 14.4 \\
Principal auditor (audit manager) & 33 & \\
Other & & \\
\hline & & \\
\hline
\end{tabular}

Descriptive statistics: Table 3 below shows the mean scores of auditors on a five point scale ranging from always to never. The mean is a middle number that represents a fundamental measure of central tendency.

Data analysis: A two stage analysis was undertaken on the data set. In the first stage, Exploratory Factor Analysis (EFA) was performed using SPSS 19.0, while in the second stage, the scales obtained as a result of the analyses in the first stage were subjected to confirmatory factor analysis (CFA) using Analysis of Moments 
Structure 19.0 with maximum-likelihood (ML) estimation, to assess internal consistency, convergent validity, discriminate validity and to determine overall fit of the measurement model.

Table 3: Means and standard Deviations

\begin{tabular}{|c|c|c|}
\hline & Mean & $\begin{array}{l}\text { Std. } \\
\text { Deviation }\end{array}$ \\
\hline $\begin{array}{l}\text { raq1: How often do you extend the scope of examination when suspicious transactions are } \\
\text { detected }\end{array}$ & $e_{1.62}$ & .89 \\
\hline raq2: How often do you think other auditors act in the above manner & 2.07 & .94 \\
\hline raq3 How often do you perform all procedures on all items in the sample & 1.80 & .85 \\
\hline raq4: How often do you think other auditors act in the above manner & 2.17 & .92 \\
\hline $\begin{array}{l}\text { raq5 How often do you research a technical issue and professional standards relevant to } \\
\text { the issues, when unsure of the correct accounting treatment }\end{array}$ & 1.68 & .93 \\
\hline raq6: How often do you think other auditors act in the above manner & 2.23 & 1.02 \\
\hline $\begin{array}{l}\text { raq7: How often do you accept client explanation and use them as a substitute for other } \\
\text { evidence that you could reasonably expect to be available }\end{array}$ & r 3.13 & 1.02 \\
\hline raq8: How often do you think other auditors act in the above manner & 3.05 & .95 \\
\hline $\begin{array}{l}\text { raq9: How often do you sign off a required audit step, which is not covered by other steps, } \\
\text { without completing, or noting the omission of the procedure }\end{array}$ & 3.74 & 1.07 \\
\hline raq10: How often do you think other auditors act in the above manner & 3.56 & .10 \\
\hline $\begin{array}{l}\text { raq11: How often do you quickly review supporting documents without paying much } \\
\text { attention to their validity or accuracy }\end{array}$ & 3.84 & 1.15 \\
\hline raq12: How often do you think other auditors act in the above manner & 3.52 & 1.11 \\
\hline $\begin{array}{l}\text { raq13: During examination, how often do you discard awkward-looking items from a } \\
\text { sample, which seem complex and/or time consuming, and replacing them with others }\end{array}$ & a 3.72 & 1.12 \\
\hline $\begin{array}{l}\text { raq14: How often do you think other auditors act in the above manner } \\
\text { Valid N (list wise) }\end{array}$ & 3.55 & 1.02 \\
\hline
\end{tabular}

Exploratory Factor Analysis: Exploratory factor analysis was used to uncover the underlying structure of a set of variables and to examine its internal reliability. Exploratory factor analysis is recommended when researchers have no preconceived hypothesis or prior theory about the nature of the underlying factor structure of their measure as such it is an inductive approach using factor loadings to uncover the factor structure of the data. Factor analysis requires two stages; factor extraction and factor rotation. Factor extraction was conducted to make an initial decision about the number of factors underlying a set of measured variables or items. Factor rotation was to statistically manipulate the results to make the factors more interpretable and to make the formal decisions about the number of the underlying factors. Exploratory factor analysis with Principal Component Analysis was employed, with an aim of empirically revealing and demonstrating the underlying structure of the preliminary model of reduced audit quality behavior. Before conducting exploratory factor analysis, the results of the Kaiser-Meyer-Olkin measure of sampling adequacy and the Bartlett's test of sphericity were examined to determine the appropriateness of factor analysis. Examination of the correlation matrix indicated that most variables had sufficient correlations to warrant using factor analytic techniques. Additionally, Bartlett's Test of Sphercity was significant (BTS value=97.915, $\mathrm{p}<0.001$ ), showing that the correlation matrix was significantly different from an identity matrix. Further, the Kaiser-Meyer-Olkin Measure of Sampling Adequacy was sufficient $(\mathrm{KMO}=.618)$ to predict that the data were likely to factor well based on correlation and partial correlation. Kaiser (1974) recommends a bare minimum of 0.5 and that values between 0.5 and 0.7 are mediocre, values between 0.7 and 0.8 are good, values between 0.8 and 0.9 are great and above 0.9 are superb. The constructs were subjected to principal axis factor analysis in order to assess its underlying structure. Principle component analysis using varimax rotation and eigenvalues greater than 1 yielded five factors. This analysis was repeated using oblimin, which yielded nearly identical results. An inspection of the scree-plot revealed a clear break after the fifth component as shown below: 
Figure 1: Scree plot diagram showing the Eigenvalues of the items

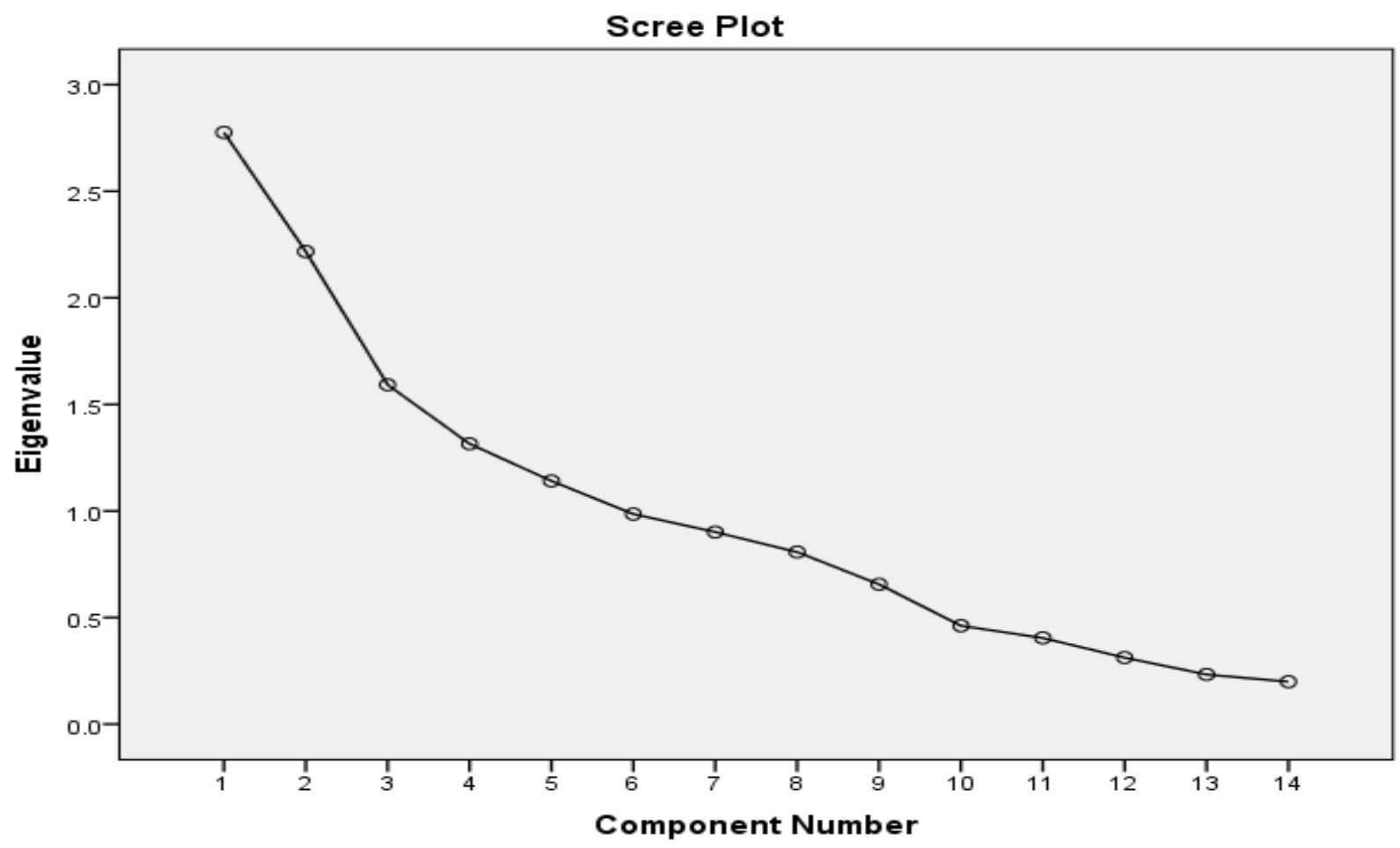

It was therefore decided to retain five factors. The five factors explained a total of $41 \%$ of the variance. To aid in the interpretation of these factors, oblimin rotation was performed. The rotated solution revealed a simple structure with all the factors showing a number of strong loadings and all variables loading substantially on only one factor.

Confirmatory Factor Analysis (CFA): Confirmatory Factor analysis (CFA) seeks to determine if the number of factors and the loadings of measured (indicator) variables on them conform to what is expected on the basis of pre-established theory. Therefore after performing exploratory factor analysis, the extracted factors were then subjected to a confirmatory factor analysis with analysis of moments of structure 19.0 (Arbuckle, 1999), to test the fit between the five-factor model and the data. The maximum likelihood estimation method was used. Exploratory factor analysis cannot assess uni-dimensionality directly, but aims to assess the factor structure of a scale. Thus, confirmatory factor analysis is considered a more powerful technique than exploratory factor analysis for such assessment (Anderson \& Gerbing, 1988, Hair, Anderson, Tatham \& Black, 1995). Further, Kline (2005) maintains there is evidence that the factor structure identified in exploratory factor analysis may turn out to have poor fit to the same data when evaluated with confirmatory factor analysis. Therefore after performing exploratory factor analysis, confirmatory factor analysis was used to determine whether the number of factors and the loadings of measured indicators (items) had conformed to what was expected, based on re-established research and theory. Empirical evidence in Confirmatory Factor Analysis is generally assessed using criteria such as the comparative fit index (CFI), the root mean square error of approximation (RMSEA), the significance of parameter estimates, and the amount of explained variance. The following goodness of fit indices was used to evaluate the Confirmatory Factor Analysis solution. Chi-square statistic; Bentler-Bonett normed fit index (NFI); comparative fit index (CFI); Root Mean square error of approximation (RMSEA). A good model fit is inferred if NFI, CFI are above .9 and RMSEA is less than .06 and $\chi^{2} / \mathrm{df}$ is between 1 and 5. The maximum likelihood estimation method (Bentler, 1995) was used for the confirmatory factor analysis. The five-factor measurement model of reduced audit quality behavior was comprised of scope, research procedures, client explanation, quick review, and examination. Two items were used to measure each of the factors. The initial standardized estimations for the hypothesized model showed that all the parameters were highly significant $(\mathrm{P}<0.001)$. The fit of model indices indicated that this measurement model did not fit to the data. The chi-square was $\left(\chi^{2}=470.47, \mathrm{df}=\right.$ 
$69, \mathrm{P}=.000, N=313)$. The CFI $=.65, \mathrm{TLI}=.54, \mathrm{NFI}=.62$, RMSEA $=0.14, \chi^{2} / \mathrm{df}=6.818$. Given that most of these indices were not within the acceptable level, a more detailed assessment was performed in an attempt to modify the model and make it more parsimonious.

Table 1: Rotated Component Matrix for Reduced Audit Quality Behavior

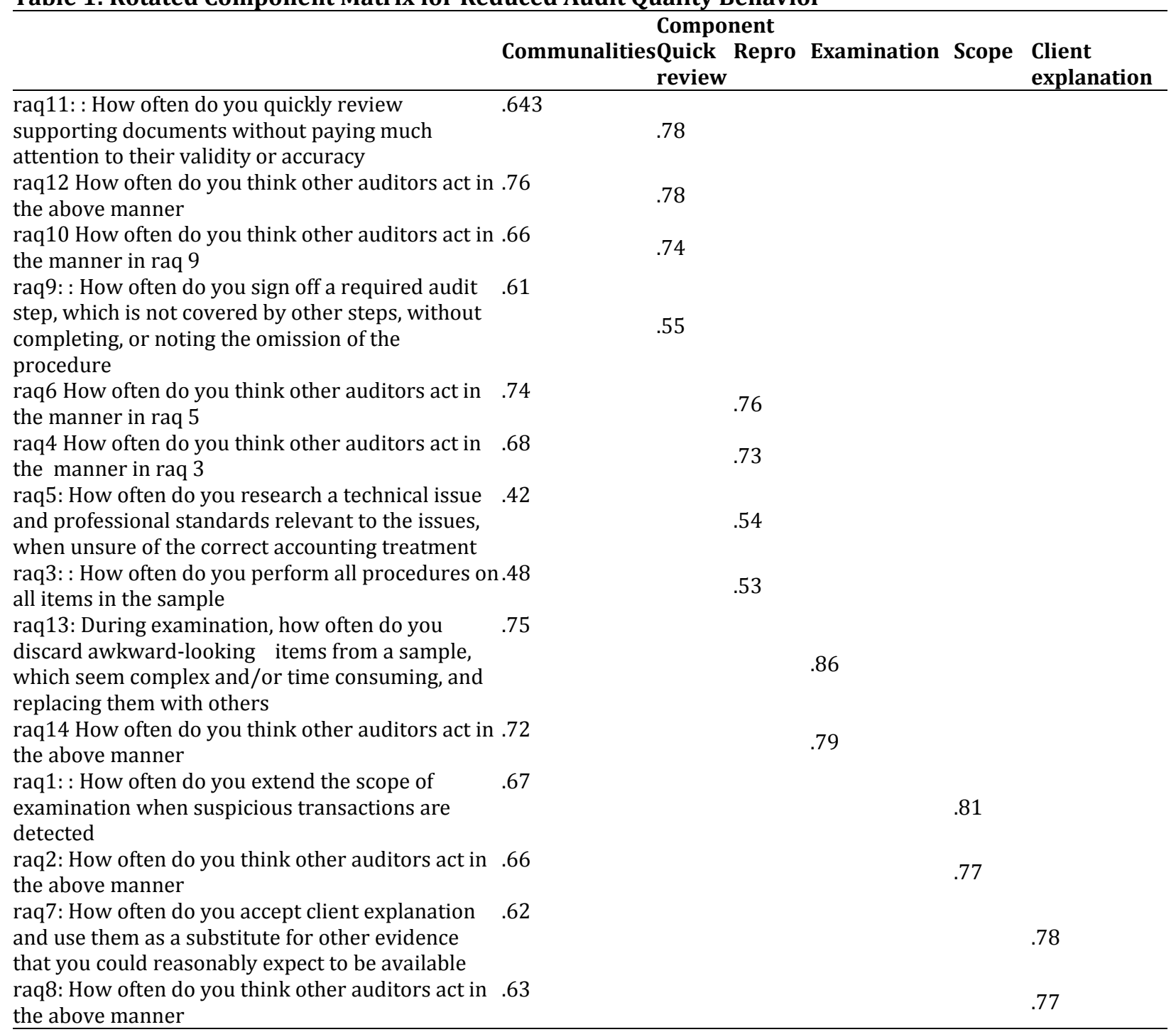

Extraction Method: Principal Component Analysis.

Rotation Method: Varimax with Kaiser Normalization.

The examination of modification indices showed that (ra5, raq6, raq9, raq2 and raq1) had large values (13.60, $12.78,5.31,5.27$ and 5.00). Therefore, it was decided to remove these five items). Additional items raq7, and raq8, were further removed because they had the lowest loadings of the remaining items of $(.68$, and .65 , respectively). These deletions did not significantly change the content of the construct as it was conceptualized because the remaining items had the highest loadings. The final model with the nine items deleted improved the fit of the model. The chi-square was $\left(\chi^{2}=.310 \mathrm{df}=1, \mathrm{P}=.86, N=313\right)$. All of GFI $=1.00$, $\mathrm{CFI}=1.00$, TLI $=1.01 \mathrm{RMSEA}=.00$, and $\chi^{2} / \mathrm{df}=.16$ are improved. Given that the model fits the data adequately and the correlations between the underlying factors are less than .85 (see the values on the double-headed arrows in Figure 1, no further adjustments were required. The standardized factor loadings for these measures were all high (above .50). This indicates that standardized parameter estimates for these measures were deemed to be statistically significant $(\mathrm{P}<0.001)$, providing uni-dimensional scales for each of the two factors. 


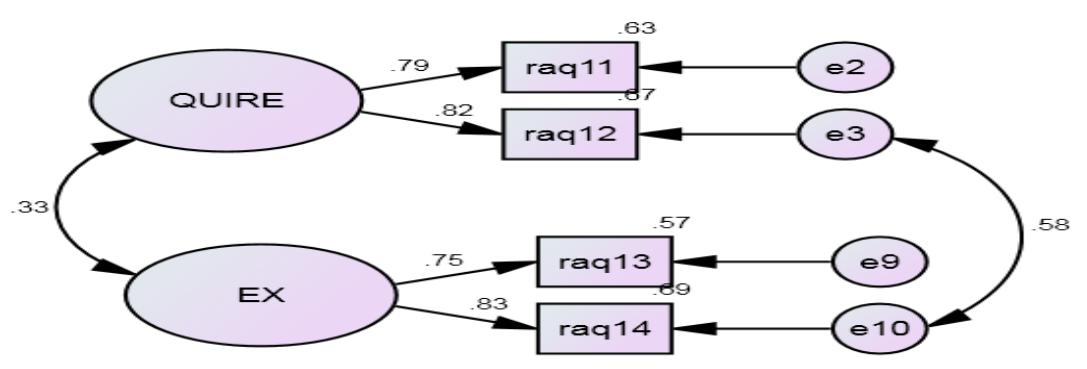

Fig 1: Measurement model of reduced audit quality behavior

Chi-square $=.310, D F=2, C M I N / D F=.155, P=.856, G F I=1.000$, CFI=1.00O, TLI=1.013, NFI=.999, RMSEA $=.000$

QUIRE= Quick review, EX= Examination

Internal Consistency: Once the uni-dimensionality of the constructs was demonstrated using confirmatory factor analysis, the reliability of each of the factor was assessed using cronbach's alpha, construct reliability (CR), and average variance extracted (AVE), and for validity using construct, convergent and discriminate. In general reliability coefficients of 0.70 or more are considered adequate (Cronbach, 1951; Nunnally, 1978; Murphy and Balzer, 1989). The values of all the constructs were above 0.70 .

Table 5: Internal consistency (Reliability Analysis)

\begin{tabular}{|c|c|c|c|c|c|c|}
\hline Construct & Items & Mean & $\begin{array}{l}\text { Standardized } \\
\text { Loading }\end{array}$ & $\begin{array}{l}\text { Cronbach's } \\
\text { alpha }(\alpha)\end{array}$ & CR & AVE \\
\hline Quick review & Raq11, raq12 & 3.68 & $\begin{array}{ll}.79 & .82\end{array}$ & 0.79 & 0.74 & 0.59 \\
\hline Examination & Raq13, raq14 & 3.64 & .83 & 0.76 & 0.74 & 0.59 \\
\hline
\end{tabular}

Note: $\mathrm{CR}=$ construct reliability; AVE = Average Variance Extraction

In using confirmatory factor analysis, composite reliability and average variance extracted were calculated from model estimates using the composite reliability formula and average variance extracted formula given by Fornell \& Larcker (1981). Bagozzi \& Yi (1988) recommended that composite reliability should be equal to or greater than .60, and average variance extracted should be equal to or greater than .50 . Based on these assessments, measures used within this study were not within the acceptable levels thus disputing the reliability of the factors as shown in Table 4.

Construct Validity: This is a scientific measurement concept composed of convergent and discriminant validity. After assessing uni-dimensionality and reliability, convergent and discriminant validity of the questionnaire were also assessed. Confirmatory factor analysis was used to assess both validities. The convergent validity is shown when each measurement item correlates strongly with its assumed theoretical factor. The validity of each scale was checked with Bentler-Bonett Normed Fit Index (NFI) obtained during confirmatory factor analysis. According to Ahire et al. (1996) this index measures the extent to which different approaches to measuring a construct produces the same results. A value of 0.90 and above 
demonstrates strong convergent validity (Hartwick \& Barki, 1994). The Bentler-Bonett coefficient for all the constructs refined after Confirmatory Factor Analysis was greater than 0.90, indicating high convergent validity. The results of average variance extracted presented in Table 4 provide an additional support for convergent validity. Discriminant validity measures the degree to which a construct and its indicators are different from another construct and its indicators (Bagozzi et al., 1991). Evidence of discriminant validity can be assessed in multiple ways. One of the ways is by examining the pattern structure coefficient to determine whether factors in measurement model are empirically distinguishable. The pattern coefficient matrix comprises the standardized factor loadings derived from Analysis of Moments of Structure (Kline, 2005. Finally, discriminant validity was assessed using two methods. First, taking Kline (2005) suggestions that the estimated correlations between factors should not be higher than .85, the measurement model was subject to this assessment and there is evidence of discriminant validity as shown in Fig 1.

\section{Discussion}

Dimensions (Scales) of Reduced Audit Quality Behavior: This study hypothesized that reduced audit quality behavior was a multi-dimensional construct. Exploratory Factor analysis of the reduced audit quality acts yielded five factors, while confirmatory factor analysis yielded two factors. This shows that reduced audit quality behavior is a two-dimension construct. The findings in this study agree with Coram et al. (2008) who found that the moral intensity of reduced audit quality acts differs. It is also in line with previous scholars (e.g. Malone \& Roberts, 1996; Coram et al., 2003; Paino et al., 2010) who found that the occurrence of the various reduced audit quality acts differs. Reduced audit quality behavior is not a uni-dimension construct as has been conceptualized by some scholars (e.g., Margheim, Kelly \& Pattison, 2005; McNamara \& Liyanarachchi, 2005; Otley \& Pierce, 1996). The findings of this research shed light on the meaning of the construct reduced audit quality behavior, extend previous research and provide a new perspective on the underlying structure of this questionnaire. The latent structure of reduced audit quality behavior seems better represented by two factors with four items. The study used a five-point Likert scale where results are based on the mean and median scores. The mean score is a middle number and represents a fundamental measure of central tendency. This implies that, a mean scored above three indicates that responses are directed towards Never and responses below three indicate responses are directed toward always. The two factors of quick review and examination had a mean of 3.68 and 3.64 respectively suggesting that there are not often engaged in by auditors. Although, International Standards on Auditing (ISA) require auditors to approach the audit with professional skepticism, some auditors in Uganda still engage in quickly reviewing documents without paying much attention to detail and discard awkward looking items from the sample during audit examination, and this seems to occur mainly in non-risky areas. This suggests that auditors consider risk before engaging in reduced audit quality behavior. This intentional behavior might be a result of lack of proper review in the audit process.

\section{Conclusion}

Our analyses showed that reduced audit quality behavior is best represented by two underlying, strongly related factors of quick review and examination. The two factors had the strongest factor loadings suggesting that they are the best proxies that can be used to measure reduced audit quality behavior. As a result of the above findings, the empirical evidence and results answer the research questions of this research and also supports the stated hypotheses of this study. Researchers in Uganda are advised to use these proxies in the study of reduced audit quality behavior.

Limitations of the study: All operational measures in behavior research, only partially capture the underlying constructs. Thus measurement errors may have reduced the reliability of the scales. This study was cross-sectional in nature. We do not know whether these results would change overtime. Longitudinal research could provide strong evidence for the two dimensions.

Recommendations: Future studies should carry out longitudinal studies to check if the results will hold after a period of time. Nevertheless, confirmatory factor analysis should be further studied. It seems clear that these findings shed light on the components and structure of reduced audit quality behavior, extend the previous research, and provide a new perspective on the underlying structure of this variable used to 
measure reduced audit quality behavior. Uganda, being a developing country, the audit market is dominated by small firms, future studies should be carried out among the "Big" four.

\section{References}

Alderman, C. W. \& Deitrick, J. W. (1982). Auditor's perceptions of time budget pressures and premature signoffs: A replication and extension. Auditing: A Journal of Practice \& Theory, 1, 54-68.

Amaratunga, D., Baldry, D., Sashar, M. \& Newton, R. (2002). Quantitative and Qualitative research in the built environment: application of mixed research approach. Work Study, 51(1), 17-31.

Anderson, J. C. \& Gerbing, D. W. (1988). Structural Equation Modeling in Practice: A Review and Recommended Two-Step Approach. Psychological Bulletin.

Arbucle, J. L. (1999). Amos 4.0 (Computer Software). Smallwaters: Chicago.

Bagozzi, R. P., Yi, Y. \& Philips, L. W. (1991). Assessing construct validity in organizational research. Administrative Science Quarterly, 36(2), 421-58

Bentler, P. M. (1995). EQS: Structural Equation Program Manual. Encino, CA: Multivariate Software, Inc

Cavana, R. Y., Delahaye, B. L. \& Sekaran, U. (2001). Applied Business Research: Qualitative and Quantitative Methods (3rd ed.). Milton, Qld: John Wiley \& Sons.

Churchill, G. A. (1979). A paradigm for developing better measures of marketing constructs. Journal of Marketing Research, 16(1), 64-73.

Coram, P., Ng, J. \& Woodliff, D. R. (2003). A survey of time budget pressure and reduced audit quality among Australian auditors. Australian Accounting Review, 13, 38-44.

Coram, P., Glavovic, A. \& Juliana, N. (2008). The moral intensity of Reduced Audit Quality Acts. Auditing: $A$ journal of practice and Theory, 27(1), 127

Cronbach, L. J. (1951). Coefficient Alpha and the Internal Structural of Tests. Psychometrica, 16(3), 297-334.

Donnelly, D. P., O'Bryan, D. \& Quirin, J. J. (2003). Auditor acceptance of dysfunctional audit behavior: an explanatory model using auditors' personal characteristics. Behavioral Research in Accounting, 15, 87-110.

Fornell, L. \& Larcker, L. (1981). Evaluating Structural Equation Models with Unobservable Variables. Journal of marketing research, 18(1), 39-50

Hair, J. F., Anderson, R. E., Tatham, R. L. \& Black, W. C. (1995). Multivariate Data Analysis with Readings (4th ed.). Englewood Cliffs, NJ: Prentice Hall.

Herrbach, O. (2001). Audit Quality, Auditor Behavior, and the Psychological Contract. European Accounting Review, 10(4), 787-82

Herrbach, 0. (2005). The Art of Compromise? The individual and organizational legitimacy of Irregular Auditing. Accounting, Auditing and accountability Journal, 18(3), 390-490

Hunt, S. D., Sparkman, R. D. \& Wilcox, J. B. (1982). Pretest in survey research: Issues and preliminary findings. Journal of Marketing Research, 19(2), 269-273

Kaiser, H. F. (1974). An index of factorial simplicity. Psychometrica, 39, 31-26

Kasigwa, G., Munene, J. C., Ntayi, J. \& Nkote, I. (2013). The Reduced Audit Quality Behavior of Auditors in Uganda. African Journal of Accounting, Economics, Finance and Banking Research, 9(9).

Kelley. T. \& Margheim, L. (1990). The Impact of time budget pressure, personality, and leadership variables on dysfunctional auditor behavior. Auditing: A Journal of Practice \&Theory, 9, 21-42.

Kelley, T., Margheim, L. \& Pattison, D. (2005). An empirical analysis of the effects of auditor time budget pressure and time deadline pressure. Journal of Applied Business Research, 21, 23-35.

Kline, R. B. (2005). Principles and Practice of Structural Equation Modeling (2nded.). New York: The Guilford Press.

Krejcie, R. V. \& Morgan, D. W., (1970). Determining sample size for research activities. Education and Psychological measurement, 30, 607-610

Lightner, S. M., Adams, S. J. \& Lightner, K. M. (1982). The influence of situational, ethical and expectancy theory variables on accountants' underreporting behavior. Auditing: A journal of practice and theory, 3, 1-12

Margheim L., Kelly T. \& Pattison, L. (2005). An Empirical Analysis of The Effects of Auditor Time Budget Pressure and Time Deadline Pressure. The Journal of Applied Business Research, 21(1), 23-36.

McNair, C. J. (1991). Proper compromises: the management control dilemma in public accounting and its impact on auditor behavior. Accounting, Organizations and Society, 16, 635-53. 
McNamara, S. (2004). Time budget pressure in auditing: an investigation into the perceived influences and behavioral effects of time budget pressure on New-Zealand auditors in public practice", University of Otago, Dunedin, unpublished Honours dissertation.

McNamara, S. \& Liyanarachchi, G. (2005). Time budget pressure and auditor dysfunctional behavior within an occupational stress model, Department of Accountancy and Business Law, University of Otago, Dunedin, working paper series.

Malone, C. F. \& Roberts, R. W. (1996). Factors associated with the incidence of reduced audit quality behaviors. Auditing: A Journal of Practice \& Theory, 15(2), 49-64.

Margheim, L. \& Pany, K. (1986). Quality control, premature signoff, and underreporting of time: Some empirical findings. Auditing: A Journal of Practice \&Theory, 7, 50-63.

Murphy, K. \& Blazer, W. (1989). Rate error and rating accuracy. Journal of applied psychology, 71(4), 619-24

Mwenda, A. (2013). The scandal in the Office of the prime Minister and Ministry of Public Service show break down of government's financial management system. The Independent p1-7

Nunnally, J. C. (1978). Psychometric theory, Mc Graw-Hill, London

Otley, D. \& Pierce, B. (1995). The control problem in public accounting firms: An empirical study of the impact of leadership style. Accounting, Organizations and Society, 20, 405-420.

Otley, D. \& Pierce, B. (1996). Auditor time budget pressure: consequences and antecedents. Accounting, Auditing and Accountability journal, 2, 31-58

Paino, H., Thani, A. \& Idris, S. (2011). Attitudes Toward Dysfunctional Audit Behavior: The Effect of Budget Emphasis, Leadership Behavior, and Effectiveness of Audit Review. Journal of Modern Accounting and Auditing, 7(12), 1344-1351.

Paino, H., Ismail, Z. \& Smith, G. M. (2010). Dysfunctional Audit Behavior: An Exploratory Study in Malaysia. Asian Review of Accounting, 18(2), 162-173

Peter, P. J. (1979). Reliability; A review of psychometric basics and recent marketing practices. Journal of Marketing Research, 169, 6-12

Pierce, B. \& Sweeney, B. (2004). Cost-quality conflict in audit firms: an empirical investigation. European accounting Review, 13(1), 415-441

Public Oversights Board. (2000). The panel on audit effectiveness report and recommendations, Stamford, CT, Public Oversight board.

Punch, K. F. (1998). Introduction to Social Research: Quantitative and Qualitative Approaches. London: Sage.

Rhode, J. G. (1978). Survey on the Influence of selected aspects of the auditor's work environment on professional performance of certified public accountants. Issued as the Independent Auditor's Work Environment: A Survey. New York, NY: American Institute of Certified Public Accountants.

Raghunathan, B. (1991). Premature signing-off of audit procedures: an analysis. Accounting Horizons, 5, 71-9.

Saunders, M., Lewis, P. \& Thornhill, A. (2009). Research Methods for Business Students, $4^{\text {th }}$ Ed. Financial TimesPrentice Hall, Harlow, Chapters 1, 273.

Transparency International. (2013). Corruption perceptions index. Available at CPI. Transparency.org/cpi2013/results/

Willet, C. \& Page, M. (1996). A survey of time budget pressure and irregular audit practices among newly qualified UK chartered accountants. British Accounting Review, 28, 101-120

Zikmund, W. G., Babin, B. J., Carr, J. C. \& Griffin, M. (2010). Business Research Method (8th Ed.). South Western Cengage Learning. 